\title{
An assessment of meaning in life-threatening illness: development of the Healing Experience in All Life Stressors (HEALS)
}

This article was published in the following Dove Press journal:

Patient Related Outcome Measures

16 February 2017

Number of times this article has been viewed

\author{
Danetta Hendricks Sloan' \\ Karlynn BrintzenhofeSzoc ${ }^{2}$ \\ Tiffany Kichline' \\ Karen Baker' \\ Jean-Paul Pinzon' \\ Christina Tafe' \\ Lingsheng $\mathrm{Li}^{\prime}$ \\ M Jennifer Cheng' \\ Ann Berger'
}

'Pain and Palliative Care, National Institutes of Health, Clinical Center, Bethesda, MD, ${ }^{2}$ School of Social Work, College of Allied Health Sciences, University of Cincinnati, Cincinnati, $\mathrm{OH}, \mathrm{USA}$
Correspondence: Danetta Hendricks Sloan

The National Institutes of Health Clinical Center, 10 Center Drive, Building I0/CRC MSC 1517, Bethesda, MD 20892, USA

Email dhendr49@gmail.com
Context: Patients with life-threatening or chronic illness report an experience of increased positive psychological, social, and/or spiritual change during diagnosis and/or treatment of their illness, even in the face of unfavorable prognosis. This transformation begins through the ability to make their life meaningful by forming meaningful connections that emerge through self-introspection and relationships with a divine entity, nature, and other people. The Healing Experience in All Life Stressors (HEALS) assessment provides a way to identify distress-causing changes that may interfere with the development of meaning and psycho-social-spiritual homeostasis. Objective: Preliminary examination of responses to items on the HEALS and examination of the factor structure.

Method: The 48-item HEALS questionnaire was developed using a multistep process: literature review for concept development, item generation from qualitative data, and face and content validity by expert panel. In the current study, HEALS was completed by 100 patients diagnosed with life-limiting disease and seen by the palliative care team at a large research institution in the US. Exploratory factor analysis techniques were used to determine scale structure of the instrument.

Results: Outcome testing of sample adequacy using Kaiser-Meyer-Olkin statistic was 0.75, which exceeds the recommended value of 0.60 . The HEALS show very good internal consistency with a Cronbach's $\alpha$ of 0.94 . Overall results of the exploratory factor analysis established a fourfactor questionnaire: 1) religion; 2) spirituality, demonstrated by a) interaction with a religious community and b) belief in higher power; 3 ) intrapersonal; and 4) interpersonal relationships expressed through psychological changes resulting in enhanced outlook and improvement in relationships with family and friends.

Conclusion: This study involved the initial step to commence the process of scale validation, with promising outcomes identifying subscales as an effective way to assess the construct of healing. These findings support further examination using cognitive appraisal and confirmatory factor analysis.

Keywords: palliative care, psycho-social spiritual assessment, validation, instrumentation

\section{Introduction}

Often patients with a life-threatening illness report an experience of increased positive psychological, social, and/or spiritual change during diagnosis and/or treatment of their illness, even in the face of unfavorable prognosis and poor physical outcomes. ${ }^{1-3}$ This phenomenon is referred to by several names such as resilience, ${ }^{4}$ traumatic growth, ${ }^{5}$ benefit-finding or stress-related growth, ${ }^{6}$ and life-transforming change (LTC). ${ }^{7}$ These constructs may differ based upon discipline; however, all terms tend to have one thing 
in common, they all describe a way of being that encompasses the ability to endure and reach a mental homeostasis in the midst of unfavorable circumstances. ${ }^{5-8}$ For instance, some literature speaks of transforming change as a construct of healing, ${ }^{7}$ and according to Johnson ${ }^{8}$ it represents processes that take place internally as opposed to externally. This finding is consistent with Quality of Life and Complementary Alternative Medicine researchers' findings that healing is a unification of mind, body, and spiritual wellness that can result in LTC and ultimately inner peace irrespective of disease outcome..$^{9,10}$ Similarly, quality of life literature speaks of healing as a relational process involving the experience of integrity and wholeness and absence of "wounding" and suffering. ${ }^{9-11}$

In the practice of medicine, clinicians tend to avoid assessment of constructs that are not well defined such as healing. However, the phenomenon, the theory of healing, and related constructs are present in literature ${ }^{7,12,13}$ with a theoretical synthesis. Assessing the processes of healing encompasses the ability to determine a patient's adjustment to life circumstances using constructs void of extraneous factors. This provides the capability of identifying distresscausing changes that may interfere with attaining psychosocial-spiritual (PSS) homeostasis. ${ }^{14,15}$ Moreover, identifying distress-causing factors will provide information required to intervene, resulting in an improvement and a positive outcome in the PSS homeostasis. Furthermore, the assessment of healing is valuable and has clinical implications in palliative medicine as it supports patient-centered care and positive outcomes of treatment. ${ }^{12,13,16,17}$ Sulmasy $^{17}$ suggests a psychological, social, and spiritual model of healing. Palliative care is concerned with the relief of pain and suffering whether physical, psychological, social, or spiritual. In fact, the Clinical Practice Guidelines for Quality Palliative Care include eight domains of care that encompass psychological, social, spiritual, religious, existential, and cultural aspects of care, ${ }^{18,19}$ which lead to a practical formula for holistic healing. Healing across all these domains is complex, and the literature does not provide a specific set of factors that result in understanding healing with a high degree of specificity (e.g., distinguishing healing from coping, resilience, etc.). What is clear in literature is that meaning making is a central component in the healing process.

Two studies were conducted by the National Institutes of Health (NIH) palliative care group with the goal of distinguishing the existential healing experience in the presence of life-threatening illness from physical wellness. ${ }^{20,21}$ The studies were completed with cardiac and cancer patients who reported positive transforming change. The results included themes that described processes of a person's ability to adapt to serious life events. Patients reported the ability to make positive meaning of their life during illness by forming meaningful connections that emerged through self-introspection and relationships with a divine entity, nature, and other people. ${ }^{6}$ Other reported themes included mindfulness, awareness of mortality, stressors, and the depth of relationships with family and friends. ${ }^{7}$

There is an overabundance of quality of life instruments that include various questions relating functionality, symptoms, and psycho-social-spiritual issues. There is also plenty of literature on the relationship between functionality and symptoms on psycho-social-spiritual outcomes. However, a comprehensive measure to provide an assessment of psycho-social-spiritual healing is not currently available. To fill this gap, researchers at the National Institutes of Health, Pain and Palliative department (NIH, PPD) developed the Healing Experience in All Life Stressors (HEALS) instrument. This article describes the process in which we begin to standardize quantitative measures of psycho-social-spiritual healing for patients who have been diagnosed with a serious illness.

\section{Methods}

Investigators at the NIH, PPD completed a multistep process, as recommended for instrument development in the construction of the HEALS assessment tool. ${ }^{22}$ Though many survey instruments exist in palliative care and quality of life research, our goal for this study was to develop one comprehensive tool to assess "healing" using psychological, social, religious, and spiritual items.

The conceptual underpinning of HEALS materialized from palliative care providers' observations of psychological, social, and spiritual well-being through the adversities of serious terminal illnesses that often led to death. An extensive and focused review of the literature exposed a gap in the knowledge of what represents healing, what does not, and the interaction of other constructs. Researchers at the NIH utilized SCOPUS with search terms such as ["quality of life"], ["posttraumatic growth" OR "post-traumatic growth" OR "post traumatic growth"], ["benefit-finding”], and ["palliative care" AND "healing"]. To reduce false hits, each search was restricted to two SCOPUS databases: "health sciences" and "social sciences \& humanities". Additional searches were completed using root keywords of healing with psychosocial aspects; cancer; coping and adaptation; life-threatening/terminal; lived experience; resilience; selfefficacy; and survivorship. 


\section{Instrument development}

To design appropriate items for the questionnaire, the findings from the review of the literature were used in a qualitative study to conceptualize, define, and identify underlying constructs related to healing. Results of the initial qualitative inquiry established processes of independent LTC in lifethreatening illness. ${ }^{4}$ Results from other qualitative studies found that psycho-social and spiritual themes contributed to ones' adjustment to healing after LTCs in people diagnosed with cancer and cardiac diseases. ${ }^{4,6,7}$ We categorized and describe these themes as interpersonal and intrapersonal change through psycho-social and spiritual adaptation. Overall, the integration of literature and patient interviews informed the development of items to assess a patients' state of or progression toward psycho-social-spiritual healing.

To assess face and content validity, a jury of experts from a team of palliative care providers consisting of physicians, nurses, social workers, chaplains, and a scientist specializing in instrument development, as well as behavioral scientists, reviewed each item. The review resulted in a reduction from 100 to 54 items. A 5-point Likert-type scale was the response option selected to be of most value for the HEALS. This response set ranges from one to five with the following anchors: 1 "strongly disagree"; 2 "disagree"; 3 "neither agree or disagree agree"; 4 "agree"; and 5 "strongly agree". Six of the items were expected to need reverse coding. For pilot testing of the HEALS, instructions direct respondents to refer to "the last 30 days including today".

\section{Pilot study}

The NIH office of Human Subjects Research Protection approved the study including the data collection and consent process. The pilot study was undertaken as the preliminary examination of responses to items on the HEALS. The goal of the pilot study was to explore the factor structure with a planned second study with a much larger sample size to conduct confirmatory factor analysis. ${ }^{23,24}$ Participants in this study were patients receiving treatment at the NIH Clinical Center and seen by the Pain and Palliative Care Service (PPCS). One hundred participants diagnosed with chronic and/or life-limiting disease completed the HEALS survey. With $20 \%$ of the age category missing, the sample mean age was 51 years with a standard deviation of 16.3. Gender distribution was approximately equal with males making up $53 \%$ of the sample. Forty-nine percent of the participants reported being married during the initial intake to the clinical center with $20 \%$ reporting never married and others divorced. Participant's self-reported ethnicity showed that $75 \%$ were non-Hispanic White and 16\% African American.

\section{Statistical analysis}

With a 2:1 ratio of participant to item, 100 surveys completed by patients prior to their clinical appointment with a palliative care provider were included in the analysis. The data analysis included descriptive statistics and principle components factor analysis utilizing STATA Statistical Package 22 (Stata Corp, LP).

\section{Results}

The goal of this pilot study was to identify items that needed to be revised or removed to ensure a parsimonious scale. Prior to data reduction techniques, the Kaiser-Meyer-Olkin statistic was used to determine sampling adequacy, the outcome was 0.75 , which exceeds the recommended value of $0.60 .{ }^{23-25}$ Including 100 completed surveys, the HEALS showed very good internal consistency with a Cronbach's $\alpha$ of 0.94 . Using the principal components analysis (PCA) method of exploratory factor analysis (EFA) with an orthogonal rotation, a varimax procedure resulted in seven factors using an eigenvalue of $\geq 1.0$ as the deciding criteria. ${ }^{21}$ This explained $94 \%$ of the variance. Moderate to high factor loading values $>0.35$ were considered for this initial pilot testing step although values $>0.30$ were taken into consideration. The Cattell's scree test revealed that most of the variance was accounted for and leveled off between the fourth and fifth factors.

Of the seven rotated factors, the first factor, accounting for $36 \%$ of the variance, had 12 items with loadings well above the cutoff score of 0.35 . All of these items loaded exclusively on this one factor. The internal consistency of these 12 items was very high with a Cronbach's $\alpha$ of 0.977 , covering questions pertaining to religious beliefs and participation.

The second factor, accounting for $17 \%$ of the variance, had 13 moderate to moderately high factor loadings, ranging from 0.408 to 0.757 and a Cronbach's $\alpha$ of 0.828 . This factor seems to assess broad interaction with the world and the values/meaning placed upon those interactions.

The third factor accounted for $12 \%$ of the variance among the seven factors. Factor loadings were moderate, ranging from 0.459 to 0.621 with an overall Cronbach's $\alpha$ of 0.813 . These items seem to explain the more intimate interactions and psychological impressions consistent with themes from the original qualitative study. ${ }^{7}$

The fourth factor, accounting for $11 \%$ of the variance, had low to moderate factor loadings ( 0.395 to 0.669$)$ with a Cronbach's $\alpha$ of 0.796 . These items speak to the personal, psychological development resulting from life events.

Factor five consisted of four items that accounted for $11 \%$ of the variance. One item \#38 "no support", loaded on 
factor two 0.480 and five 0.415 . Based on previous patient interviews from the foundational qualitative study, item fit was harmonious with items on factor five, which covered family relationships, supportive family, and family burden. Cronbach's $a$ for component five is 0.873 .

Factors six and seven were refused; variance for factor six was $<8 \%$ and although it included five items with moderate factor loadings, it did not include resonance. Cronbach's $\alpha$ for this sixth factor was poor, $\alpha=0.574$. Factor seven had two items that loaded, with less than ( $8 \%$ variance). Cronbach's alpha is unremarkable. The findings on these final two factors led to a forced five-factor analysis using the same process.

The five-factor PCA did not support the retention of the fifth factor as it only included two uniquely loaded items accounting for $<7 \%$ of variance with a Cronbach's $\alpha$ of 0.557 . This model was not accepted leading to a PCA of a forced four-factor model.

Table I Rotated factor matrix for PCA of the HEALS

\begin{tabular}{|c|c|c|c|c|c|}
\hline \multirow[t]{2}{*}{ No } & \multirow[t]{2}{*}{ Item } & \multicolumn{4}{|c|}{ Factor } \\
\hline & & $\mathbf{I}$ & 2 & 3 & 4 \\
\hline 26 & My personal religious practice is important to me. & 0.940 & & & \\
\hline 25 & I find strength in my religious beliefs. & 0.934 & & & \\
\hline 24 & My religious beliefs comfort me. & 0.930 & & & \\
\hline 23 & My religious beliefs help me feel calm when faced with difficult circumstances in life. & 0.918 & & & \\
\hline 30 & My religious beliefs give me hope. & 0.913 & & & \\
\hline 6 & The connection with a higher power is important to me. & 0.905 & & & \\
\hline 14 & I believe in a higher power. & 0.865 & & & \\
\hline 28 & My participation in a religious community is an important aspect of my life. & 0.844 & & & \\
\hline 21 & I survive difficult circumstances because of a higher power. & 0.824 & & & \\
\hline 29 & I get support from my religious community. & 0.797 & & & \\
\hline 20 & I yearn for a connection with a higher power. & 0.778 & & & \\
\hline 22 & My situation has strengthened my connection to a higher power. & 0.728 & & & \\
\hline 53 & My relationships have deepened since experiencing difficult life challenges. & & 0.643 & & \\
\hline 35 & Relationships with my friends are more meaningful since my challenging situation began. & & 0.641 & & \\
\hline 40 & My friends provide the support I need during difficult times. & & 0.634 & & \\
\hline 46 & I have a heightened sense of gratitude. & & 0.574 & & \\
\hline 16 & Difficult circumstances in my life have increased my compassion toward others. & & 0.564 & & \\
\hline 17 & I have greater appreciation for my life. & & 0.559 & & \\
\hline 34 & I find meaning in helping others. & & 0.558 & & \\
\hline 41 & I seek more presence in my relationships. & & 0.537 & & \\
\hline 49 & Creative arts bring peace to my life. & & 0.533 & & \\
\hline 7 & I gain awareness from self-reflection. & & 0.518 & & \\
\hline 48 & Connecting with the peace in nature gives meaning to my life. & & 0.509 & & \\
\hline 44 & Working through my own grief has brought meaning to my life. & & 0.475 & & \\
\hline 52 & Life challenges raised my desire to be more positive. & & 0.441 & & \\
\hline 4 & I feel less stressed when I connect with others. & & 0.419 & & \\
\hline 8 & I enjoy activities that involve both mind and body, i.e., yoga, tai chi, etc. & & 0.398 & & \\
\hline 42 & I take time to be more present in the moment. & & & 0.402 & \\
\hline 12 & I accept things that I cannot change. & & & 0.758 & \\
\hline 45 & I have a sense of peace in my life. & & & 0.726 & \\
\hline I & I feel an inner calm that brings me peace. & & & 0.719 & \\
\hline 43 & My experience with multiple losses (death, divorce, competency, physical disability, etc.) & & & 0.571 & \\
\hline & has made it hard to be hopeful during difficult times. & & & & \\
\hline $\mathrm{II}$ & I feel calm even though I am not in control of my situation. & & & 0.554 & \\
\hline 9 & I am content with my life. & & & 0.525 & \\
\hline 19 & I no longer focus on "the little things". & & & 0.479 & \\
\hline 18 & I want to make the most of my life. & & & 0.451 & \\
\hline 39 & I am confident that my medical caregivers will respond to my needs. & & & 0.423 & \\
\hline 2 & I feel isolated. & & & 0.418 & \\
\hline 3 & I have a sense of purpose in my life. & & & 0.408 & \\
\hline 36 & Connection with my family has become my highest priority. & & & & 0.845 \\
\hline 47 & Relationship with my family is more meaningful. & & & & 0.775 \\
\hline 37 & Support from my family lifts my spirits, which gives me hope during difficult times. & & & & 0.744 \\
\hline 38 & I am not getting the support I need. & & & & 0.495 \\
\hline
\end{tabular}

Abbreviations: HEALS, Healing Experience in All Life Stressors; PCA, principal component analysis. 
Results of the four-factor analysis, depicted in Table 1, indicate unique, strong factor loadings, a strong foundation for domain definition, which will lead to a confirmatory factor analysis in the next round of the study. The four-factor model explains $96 \%$ of the overall variance observed. Using the varimax orthogonal rotation model, the first factor had 12 items and accounted for $42 \%$ of the variance with a Cronbach's $\alpha$ of 0.977 . Loadings for this domain remained high, consistent with previous model loadings. The 12 items on this factor focused on religion.

The second factor included 15 items accounting for $25 \%$ of variance and demonstrated very good reliability with a Cronbach's $a$ of 0.877 . Review of the factor revealed items relating to an individual's outward interaction with others and the development of meaning.

The third factor loading with 12 items accounting for $21 \%$ of variance had equally strong reliability results, Cronbach's $a=0.843$. Items in this factor capture spiritual issues - peace and acceptance - that seemed to develop out of life events.

The fourth factor, accounting for $11 \%$ of variance, produced good reliability (Cronbach's $\alpha=0.827$ ) and included four items. These items portray the importance of family in the progression toward overall healing during life challenges.

Of the remaining eleven items, eight variable items with loadings $<0.35$ being deleted (6) or revised (2). Three items,

Table 2 Deleted, revised, and retained items

\begin{tabular}{|c|c|c|}
\hline No & \multicolumn{2}{|l|}{ Item } \\
\hline \multicolumn{3}{|c|}{ Deleted } \\
\hline 51 & \multicolumn{2}{|c|}{ Caring for my pet(s) gives meaning to my life. } \\
\hline 10 & \multicolumn{2}{|c|}{ I enjoy helping others. } \\
\hline 15 & \multicolumn{2}{|c|}{ Taking care of me is my responsibility. } \\
\hline 27 & \multicolumn{2}{|c|}{ My values shape the way I live my life. } \\
\hline 32 & \multicolumn{2}{|c|}{$\begin{array}{l}\text { I feel that I have a meaningful connection with people at my } \\
\text { workplace. }\end{array}$} \\
\hline 54 & \multicolumn{2}{|c|}{$\begin{array}{l}\text { I have access to the information I need to make informed decisions } \\
\text { about life. }\end{array}$} \\
\hline \multicolumn{3}{|c|}{ Revised } \\
\hline \multirow[t]{2}{*}{33} & Original & Work gives me a sense of purpose during difficult times. \\
\hline & New & $\begin{array}{l}\text { Doing something I am passionate about (work, hobbies, } \\
\text { volunteering, my church, reading groups, etc.) gives me } \\
\text { purpose during difficult times. }\end{array}$ \\
\hline \multirow[t]{2}{*}{13} & Original & I am not afraid to die. \\
\hline & New & $\begin{array}{l}\text { Working through thoughts about the possibility of dying } \\
\text { brought meaning to my life. }\end{array}$ \\
\hline \multicolumn{3}{|c|}{ Retained } \\
\hline 5 & \multicolumn{2}{|c|}{$\begin{array}{l}\text { It is difficult to ask others for help because I do not want to } \\
\text { burden them. }\end{array}$} \\
\hline 50 & \multicolumn{2}{|c|}{ Life challenges interfere with activities that are important to me. } \\
\hline 31 & \multicolumn{2}{|c|}{$\begin{array}{l}\text { Lack of support prevents me from dealing with my current } \\
\text { situation. }\end{array}$} \\
\hline
\end{tabular}

with factor loadings $<0.35$ were retained without revision (Table 2). These items were kept for further testing due to patient feedback per palliative care providers and patient interview outcomes of the qualitative study that led to development of the HEALS.

\section{Discussion}

Research and attention is moving toward treatment and outcomes of disease focusing on inner healing, encompassing the whole person. ${ }^{10,17}$ The HEALS was developed to better understand the mechanism of the inner healing process, and its reliability and validity testing is underway. This article is the first in a series of three, focusing on the development process of items and scale construction of the HEALS. Based on these findings, items were deleted and revised (Table 2). Further testing of the HEALS through cognitive interviewing, as one of the initial steps, will be conducted to ascertain the participants understanding of the items and the process they underwent in selecting their responses. ${ }^{26}$

The initial process steps for the HEALS instrument began with literature review, qualitative inquiry, and rating from expert review, while also considering current psychosocial spiritual questionnaires to avoid redundancy. These steps led to the current pilot study, which explored response patterns from 100 patients that completed the HEALS while waiting for a palliative care appointment. A summary of the findings highlights catalysts of healing within the midst of life's most difficult circumstances. Final determination is not possible at this stage of development; however, findings suggest a promising outcome. For instance, results from factor item groupings trend toward four distinct themes summarized as: 1) religion - demonstrated by interaction with a religious community and belief in higher power; 2) spirituality - meaning making through outward interactions; 3 ) intrapersonal relationship - expressed through psychological changes resulting in an enhanced outlook; and 4) interpersonal relationship - relationships with family and friends.

The concept of religion, which may differ based upon culture and preference, ${ }^{16}$ generally includes beliefs in a deity and the routine practice of attending church or a connection with a church as depicted in the current outcome. ${ }^{27}$ While there may be overlap between religion and spirituality, fundamentally, spirituality is thought of as something meaningful to life that initiates transcendence, ${ }^{16}$ as demonstrated by responses in domain two that speak to meaningful interactions.

Domain three exhibits the integration of thoughts and feelings (intrapersonal) that may influence the outcome of a healing experience followed by question items in the fourth 
domain that depict the result of social interactions that may influence the ability to obtain inner healing in the midst of life-limiting illness. ${ }^{17}$

Research literature concurs that the biomedical approach to healing must shift to encompass whole person healing as outlined by the palliative model of care..$^{10,17,28}$ The WHO's definition of health is "a dynamic state of complete physical, mental, spiritual and social well-being and not merely the absence of disease or infirmity." ${ }^{29}$ Health-care providers must recognize that, in informing patients that they have a life-threatening illness, it is not just about the physical diagnosis but also its impact on the mental and spiritual being, having secondary effects on social well-being. The goal of palliative care providers is to support patients in maintaining quality of life. A need exists for a definitive measure that will provide a framework to assess patients' progression toward healing that is not limited to physical outcome.

\section{Clinical implications}

The HEALS instrument may prompt self-reflection of inner healing for patients living with progressive chronic and/or life-threatening illnesses. After reviewing responses, the instrument facilitates clinicians in having focused and indepth conversations with patients on sources of LTC and their personal growing edges. Moreover, in hospital settings, usually the palliative care physician has initial contact with the patient. Having a glimpse of the patient's outlook on life and potential to progress toward a healing outcome will help the physician and team establish rapport while obtaining information to help the team determine where to intervene, prior to in-depth assessments that follow this initial consultation. As health-care providers, we recognize that chronic and/ or life-threatening illnesses force patients to question their mortality and the meaning of their lives. Nevertheless, in many circumstances, chronic and/or life-threatening illness can give patients' lives greater meaning and purpose - the HEALS instrument is one way to begin this conversation.

\section{Conclusion}

This study involves the initial step to commence the process of scale validation. Currently, further testing of the HEALS through a cognitive interviewing technique is underway. Cognitive interviewing takes place after questionnaire development but prior to field testing for validation of the final instrument. ${ }^{26}$ This process will provide further insight into how each participant interprets the survey items and how they choose to answer the questions based on their understanding. For this second part of testing, a study population that is diverse in age, cultural background, socioeconomic, and health status will be invited to participate. We hope to create a questionnaire that is generalizable and feasible to implement in a clinical setting.

\section{Acknowledgments}

The Intramural Research Program of the NIH, Clinical Center supported this research. The authors gratefully acknowledge Erin Mistretta, NIH Summer Intern 2016, for her contribution to this project.

\section{Disclosure}

The authors report no conflicts of interest in this work.

\section{References}

1. Andrykowski M, Lykins E, Floyd A. Psychological health in cancer survivors. Semin Oncol Nurs. 2008;24(3):193-201.

2. Folkman S. Stress, coping, and hope. Psychooncology. 2010;19(9):901-908.

3. Hefferon K, Grealy M, Mutrie N. Post-traumatic growth and life threatening physical illness: a systematic review of the qualitative literature. Br J Health Psychol. 2009;14(pt 2):343-378.

4. Rutter M. Implications of resilience concepts for scientific understanding. Ann N Y Acad Sci. 2006;1094(1):1-12.

5. Tedeschi RG, Calhoun LG. Posttraumatic growth: conceptual foundations and empirical evidence. Psychol Inq. 2004;15(1):1-18.

6. Helgeson VS, Reynolds KA, Tomich PL. A meta-analytic review of benefit finding and growth. J Consult Clin Psychol. 2006;74(5):797-816.

7. Skeath P, Norris $S$, Vani K, et al. The nature of life-transforming changes among cancer survivors. Qual Health Res. 2013;23(9):1155-1167.

8. Johnson J. An overview of psychosocial support services: resources for healing. Cancer Nurs. 2000;23(4):310-313.

9. Mount B, Boston P, Cohen R. Healing connections: on moving from suffering to a sense of well-being. J Pain Symptom Manage. 2007;33(4):372-388.

10. Ingram A. A paradigm shift: healing, quality of life, and a professional choice. J Pain Symptom Manage. 2014;47(1):198-201.

11. Mount B. Healing, quality of life, and the need for a paradigm shift in health care. J Palliat Care. 2013;29(1):45-48.

12. Mount B, Kearney M. Healing in palliative care: charting our way forward. Palliat Med. 2003;17:657-658.

13. Meza JP, Fahoome GF. The development of an instrument for measuring healing. Ann Fam Med. 2008;6(4):355-360.

14. Zabora J, Brintzenhofeszoc K, Curbow B, Hooker C, Piantadosi S. The prevalence of psychological distress by cancer site. Psychooncology. 2001;10(1):19-28.

15. Berger A, editor. Principles and Practice of Palliative Care and Supportive Oncology. 4th ed. New York: Lippincott Williams \& Wilkins; 2012.

16. Salsman J, Fitchett G, Merluzzi T, Sherman A, Parks C. Religion, spirituality, and health outcomes in caner: a case for a meta-analytic investigation. Cancer. 2015;121(21):3754-3759.

17. Sulmasy D. A biopsychosocial-spiritual model for the care of patients at the end of life. Gerontologist. 2002;42(si3):24-27.

18. Center to Advance Palliative Care. A Palliative Care Tool Kit and Resource Guide. Available from: https://media.capc.org/filer public/0f/2f/0f2f8662-15cf-4680-baa8-215dd97fbde6/payer-providertoolkit-2015.pdf. Accessed December 28, 2016.

19. National Consensus Project for Quality Palliative Care. Clinical Practice Guidelines for Quality Palliative care. 2016. Available from: http://www. nationalconsensusproject.org/guideline.pdf. Accessed May 12, 2016.

20. Holder G, Young W, Nadarajah S, Berger A. Psychosocial experiences in the context of life threatening illness: the cardiac rehabilitation patient. Palliat Support Care. 2015;13(3):1-8. 
21. Young W, Nadarajah S, Skeath P, Berger A. Spirituality in the context of life threatening illness and life transforming change. Palliat Support Care. 2014;13(3):1-8.

22. Patrick D, Burke L, Gwaltney C, et al. Content validity: establishing and reporting the evidence in newly developed patient-reported outcomes (PRO) instruments for medical product evaluation: ISPOR PRO good research practices task force report: part 1 - eliciting concepts for a new PRO instrument. Value Health. 2011;14(8):967-977.

23. Pett M, Lackey N, Sullivan J. Making Sense of Factor Analysis: The Use of Factor Analysis for Instrument Development in Health Care Research. Thousand Oaks, CA: Sage Publications, Inc; 2003.

24. Swisher L, Beckstead J, Bebeau M. Factor analysis as a tool for survey analysis using a professional role orientation inventory as an example. Phys Ther. 2004;84(9):784-799.
25. Kaiser H. An index of factorial simplicity. Psychometrika. 1974;39: 31-36.

26. Willis G. Cognitive Interviewing: A Tool for Improving Questionnaire Design. California: Sage Publications, Inc; 2005.

27. The Pew Center. U.S. Public Becoming Less Religious. 2016. Available from: http://www.pewforum.org/2015/11/03/u-s-public-becoming-lessreligious/. Accessed June, 2016.

28. Kearney M. A Place of Healing: Working with Suffering in Living and Dying. Oxford, UK: Oxford University Press; 2000.

29. Preamble to the Constitution of the World Health Organization as Adopted by the International Health Conference, New York, June 19-22, 1946; signed on 22 July 1946 by the representatives of 61 States (Official Records of the World Health Organization, no. 2, p. 100) and entered into force on 7 April 1948.
Patient Related Outcome Measures

\section{Publish your work in this journal}

Patient Related Outcome Measures is an international, peer-reviewed, open access journal focusing on treatment outcomes specifically relevant to patients. All aspects of patient care are addressed within the journal and practitioners from all disciplines are invited to submit their work as well as healthcare researchers and patient support groups.

\section{Dovepress}

The journal is included in PubMed. The manuscript management system is completely online and includes a very quick and fair peer-review system. Visit http://www.dovepress.com/testimonials.php to read real quotes from published authors.

Submit your manuscript here: http://www.dovepress.com/patient-related-outcome-measures-journal 